\title{
Self organization of shear bands in stainless steel
}

\author{
Q. Xue, M.A. Meyers*, V.F. Nesterenko \\ Department of Mechanical and Aerospace Engineering, University of California, San Diego, La Jolla, CA 92093, USA
}

Received 22 April 2002; received in revised form 12 May 2004

\begin{abstract}
The spatial distribution of shear bands was investigated in 304L stainless steel through the radial collapse of a thick-walled cylinder under high-strain-rate deformation $\left(\sim 10^{4} \mathrm{~s}^{-1}\right)$. The shear-band initiation and propagation were also examined. Self-organization of multiple adiabatic shear bands was observed. The effect of grain size on spacing of shear bands was investigated at four different grain sizes: $30 \mu \mathrm{m}$, $50 \mu \mathrm{m}, 140 \mu \mathrm{m}$ and $280 \mu \mathrm{m}$. A single crystal with a similar composition was also tested. The experimental results show only a modest variation of shear-band spacing within the investigated grain size range. Three principal mechanisms are considered to be active in initiation: (a) momentum diffusion by stress unloading, (b) perturbation in the stress/strain/temperature fields, (c) microstructural inhomogeneities. The observed shear-band spacing is compared with existing theories; Grady-Kipp and Wright-Ockendon-Molinari theories. These are one-dimensional theories that do not consider the evolution in spacing as the shear bands grow. A discontinuous growth mode for shear localization under periodic perturbation is applied and predicts spacings in good agreement with observations. Self-organized initiation and propagation modes are discussed in relation to the interaction among the nucleus and well-developed shear bands.
\end{abstract}

(C) 2004 Elsevier B.V. All rights reserved.

Keywords: Shear bands; Dynamic deformation; Stainless steel; Self organization

\section{Introduction}

Thermally-assisted shear localization is one of the most important deformation and failure mechanisms in materials subjected to high strain rate deformation. Initial perturbations lead to a non-uniform distribution of temperature, which promotes localized softening and accelerates catastrophic failure. Adiabatic shear bands have been extensively studied [1-3] since the mechanism was described by Zener and Hollomon [4]. A significant body of research has been carried out, correlating both the thermomechanical response and metallurgical characteristics with the sensitivity to shear localization. The perturbation analysis [5-8] was successfully used to model the evolution of localization. This evolution was experimentally investigated under controlled conditions by Marchand and Duffy [9], among others.

In most studies, isolated bands were investigated. Nevertheless, multiple shear bands are often found in dynamic deformation events, such as explosion and impact. The evolution of multiple shear bands exhibits some features of

\footnotetext{
* Corresponding author. Tel.: +1 858534 4719; fax: +1 8585345698 .

E-mail address: mameyers@mae.ucsd.edu (M.A. Meyers).
}

self-organization. Shear bands were first shown by Bowden [10] to have a characteristic periodic spacing. Shockey [11] used an expanding cylinder accelerated by explosives and were able to determine the spacing of shear bands in steels. Grady [12], Grady and Kipp [13], Wright and Ockendon [14], and Molinari [15] developed theoretical predictions for shear band spacing that represent a beginning of our understanding of their collective behavior. More recently, Nesterenko et al. [16,17] developed an explosive testing method using a thick-walled cylinder specimen, which was successfully used to investigate the spacing of shear bands. This method has been successfully used by Nesterenko et al. in titanium [18,19], copper [17], tantalum [20], and Ti-6Al-4V [21-23]. It was also used to demonstrate the importance of shear localization in granular materials $[24,25]$. This subject is comprehensively reviewed in [26,27]. Preliminary results on self-organization of shear bands in 304 SS were recently presented [28,29].

The purpose of this paper is to extend these findings by characterizing the evolution of multiple shear bands in a typical F.C.C. material (stainless steel), to analyze the spacing characters and to compare it with the existing theories. For the first time, the effects of microstructural variables (grain size and annealing) on shear-band sensitivity, nucleation, and 
spatial pattern are investigated. A two-dimensional model for evolving shear-band spacing, proposed for Ti-6Al-4V [23], is extended to the present case.

\section{Experimental procedure}

The experimental configuration of the thick-walled cylinder explosion technique is described elsewhere [17-19]. A tubular specimen is sandwiched between a copper driver tube and a copper stopper tube and is collapsed inwards by the detonation of explosives on the outer surface. The internal diameters of copper were selected to produce a prescribed and controlled final strain. In some special cases a central steel rod was also used.

The maximum shear strain occurs on the internal surface of the cylindrical specimen, and thus shear bands preferentially initiate there. Fig. 1 shows a schematic with shear bands initiating in the internal surface. After each experiment, the cylinders were sectioned and polished. The lengths of shear bands, $l_{i}$, the edge displacements, $\delta_{i}$, the average radius of final internal boundary, $R_{\mathrm{f}}$, and the angle between spatial position from origin, $\Psi_{i}$, were measured as shown in Fig. 1. In order to compare the deformation at the different positions on the specimen, an effective strain is calculated from:

$\varepsilon_{\mathrm{ef}}=\frac{2}{\sqrt{3}} \varepsilon_{\mathrm{rr}}=\frac{2}{\sqrt{3}} \ln \left(\frac{r_{0}}{r_{\mathrm{f}}}\right)$

where $r_{0}, r_{\mathrm{f}}$ are the initial and final radii of a reference point. The effective global strain at the internal boundary of the specimen is considered a characteristic value of deformation since all the specimens have the same initial dimensions. Based on the number of distinguishable shear bands, the average spacing between them is:

$L=\frac{\Psi_{i} R_{\mathrm{f}}}{n_{i} \sqrt{2}}$

where $n_{i}$ is the number of shear bands at the particular region from the first band to $i$ th band and $\Psi_{i}$ is the corresponding

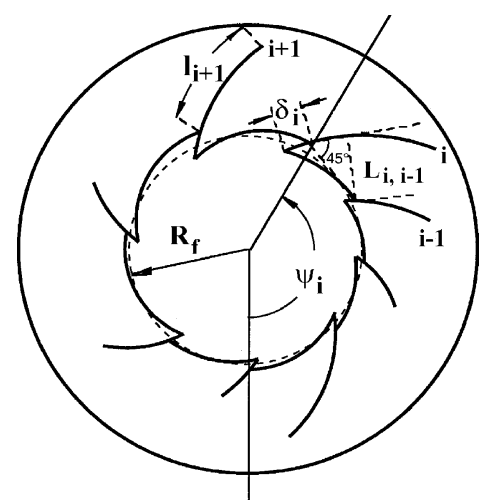

Fig. 1. Schematic representation of shear-band pattern in collapsing cylinder experiments and the basic experimental measurements that can be made. angle for this region. If $n_{i}=n_{\text {total }}, \Psi_{i}=2 \pi$. The spacing between shear bands decreases as plastic deformation proceeds. This effect was subtracted from the results with an appropriate correction. Thus, the spacings represent values at the initiation of the bands. The geometrical configuration contribution to the spacing variation was removed from the calculation of the shear band spacing by considering the smallest effective strain as the initial stage of shear localization. Hence, the spacing of shear bands can be expressed as:

$L=\frac{\Psi_{i} R_{\mathrm{f}}}{n_{i} \sqrt{2}}\left(\frac{R_{\mathrm{f} 0}}{R_{\mathrm{f}}}\right) \cong \frac{\sum_{i} L_{i, i-1}}{n_{i}}\left(\frac{R_{\mathrm{f} 0}}{R_{\mathrm{f}}}\right)$

where $R_{\mathrm{f} 0}$ is the radius of the specimen at shear band initiation, and $R_{\mathrm{f}}$ is the final radius, at any larger effective strain. $L_{i, i-1}$ is defined as the spacing between $i$ th and $i-1$ th shear bands in Fig. 1. Since $R_{\mathrm{f}}<R_{\mathrm{f} 0}$, the corrected spacing based on the final configuration has a lower value.

An austenitic stainless steel (SS) AISI 304L (T-304L) was selected to investigate the evolution of shear band spacing. The as-received SS 304L bar, with a diameter of one inch, was solution treated (average grain size of $30 \mu \mathrm{m}$ ). The heat treatment conditions were selected to provide a wide variation of grain sizes: $800^{\circ} \mathrm{C} / 3 \mathrm{~h}, 1050^{\circ} \mathrm{C} / 3 \mathrm{~h}$, $1280^{\circ} \mathrm{C} / 3 \mathrm{~h}$, and $1330^{\circ} \mathrm{C} / 24 \mathrm{~h}$, followed by water quenching. The $800^{\circ} \mathrm{C} / 3 \mathrm{~h}$ annealed SS $304 \mathrm{~L}$ has the same grain size as the as-received steel. The grain size of the steels annealed at $1050^{\circ} \mathrm{C} / 3 \mathrm{~h}, 1280^{\circ} \mathrm{C} / 3 \mathrm{~h}$ and $1330^{\circ} \mathrm{C} / 24 \mathrm{~h}$ are $50 \mu \mathrm{m}, 140 \mu \mathrm{m}$, and $280 \mu \mathrm{m}$, respectively. A single crystal of $\mathrm{Fe}-\mathrm{Ni}-\mathrm{Cr}$ alloy was also tested in the same configuration. The mill certificate for the 304L stainless steel lists the following composition: $\mathrm{Cr}(18.18 \%), \mathrm{Ni}(9.22 \%), \mathrm{Mn}$ $(1.42 \%), \mathrm{N}(0.25 \%), \mathrm{C}(0.017 \%), \mathrm{Si}(0.44 \%)$. The single crystal has a composition of $\mathrm{Cr}(15 \%)$ and $\mathrm{Ni}(15 \%)$. The total alloy content was approximately the same. Quasi-static and dynamic compression tests were carried out for materials under all different heat treatment conditions. The high-strain-rate mechanical response was measured by means of compressive split-Hopkinson bar experiments.

The initial internal and external diameters of the thick-walled cylindrical specimen were $14 \mathrm{~mm}$ and $21 \mathrm{~mm}$, respectively. The strain rate in the experiments was $\dot{\gamma}=$ $6 \times 10^{4} \mathrm{~s}^{-1}$. The thermal conductivity and heat capacity for stainless steel are, respectively, $k=14.7 \mathrm{~J} / \mathrm{s} \mathrm{m} \mathrm{K}$ and $C$ $=500 \mathrm{~J} / \mathrm{kg} \mathrm{K}$. The strain rate sensitivity, $m=0.012$, was calculated from the quasi-static and dynamic tests; and the thermal softening factor is $a=7.2 \times 10^{-4} \mathrm{~K}^{-1}$ from [30]. The strain hardening index was measured and compared with previous experimental data [30]. The tensile properties listed by the manufacturer are: $\sigma_{0.2}=249 \mathrm{MPa}, \sigma_{\mathrm{t}}$ $=641 \mathrm{MPa}$, elongation $=58 \%$.

\section{Theoretical predictions}

The current theories for predicting shear band spacing can be classified into two types. They start from the 
one-dimensional momentum and energy conservation equations, but assume different mechanisms.

The concept of momentum diffusion was proposed by Grady and Kipp (GK) [13]. The basic idea lies in the unloading from the center of the SB and is inspired by Mott's [31] seminal fracture work. The momentum diffusion due to the unloading creates a rigid region around the shear bands. This material is shielded from further shear band initiation. Grady and Kipp [13] used a simple constitutive equation, without work hardening or strain-rate sensitivity:

$\tau=\tau_{0 \mathrm{~d}}\left[1-a\left(T-T_{0}\right)\right]$

The predicted shear band spacing, $L$, is

$$
\begin{aligned}
L_{\mathrm{GK}} & =2\left[\frac{9 k C}{\dot{\gamma}_{0}^{3} a^{2} \tau_{0 \mathrm{~d}}}\right]^{1 / 4} \\
& =2 \pi\left[\frac{k C}{\dot{\gamma}_{0}^{3} a^{2} \tau_{0}}\right]^{1 / 4} \frac{9^{1 / 4}}{\pi}\left(\frac{\tau_{0}}{\tau_{0 \mathrm{~d}}}\right)^{1 / 4}
\end{aligned}
$$

where $a$ is the thermal softening coefficient, $k$ the thermal conductivity, $C$ the heat capacity, $\tau_{0}$ and $\tau_{0 \mathrm{~d}}$ the shear flow stresses under quasistatic and dynamic conditions, respectively. It is assumed that within a well-developed shear band the shear stress is reduced to zero; this corresponds to the later stages of shear localization with well developed shear bands.

The second approach uses the perturbation analysis at the critical transition from stable to unstable plastic deformation. Grady [12], and Wright and Ockendon (WO) [14] developed this analysis for the one-dimensional simple shear case. They assumed that the fastest growing perturbation wavelength associated with the instability produced the minimum spacing. They used a constitutive equation with strain-rate sensitivity (but no work hardening):

$\tau=\tau_{0}\left[1-a\left(T-T_{0}\right)\right]\left(\frac{\dot{\gamma}}{\dot{\gamma}_{0}}\right)^{m}$

where $\dot{\gamma}$ is a reference strain rate, $\tau_{0}$ the quasistatic strain rate, and $m$ the strain-rate sensitivity. The calculated spacing of shear bands is:

$L_{\mathrm{WO}}=2 \pi\left[\frac{m^{3} k C}{\dot{\gamma}_{0}^{3} a^{2} \tau_{0}}\right]^{1 / 4}=2 \pi\left[\frac{k C}{\dot{\gamma}_{0}^{3} a^{2} \tau_{0}}\right]^{1 / 4} m^{3 / 4}$

Molinari [15] modified the WO model by incorporating the effect of strain hardening. A more complicated expression for the spacing was obtained. It is also based on the growth of perturbations. His prediction for spacing (without strain hardening effect) is:

$$
\begin{aligned}
L_{\mathrm{M}} & =2 \pi\left[\frac{k C m^{3}\left(1-a T_{0}\right)^{2}}{(1+m) \dot{\gamma}_{0}^{3} a^{2} \tau_{0}}\right]^{1 / 4} \\
& =2 \pi\left[\frac{k C}{\dot{\gamma}_{0}^{3} a^{2} \tau_{0}}\right]^{1 / 4}\left[\frac{m^{3}\left(1-a T_{0}\right)^{2}}{1+m}\right]^{1 / 4}
\end{aligned}
$$

Table 1

Zerilli-Armstrong constitutive equation and coefficients for AISI 304L SS

\begin{tabular}{lc}
\hline $\mathrm{C}_{0}$ & -76.9 \\
$K_{1}$ & 0.75 \\
$C_{2}$ & 2340 \\
$C_{3}$ & 0.0016 \\
$C_{4}$ & 0.00008 \\
$C_{n}$ & 0.36 \\
\hline
\end{tabular}

FCC : $\quad \sigma=\mathrm{C}_{0}+k_{1} d^{-1 / 2}+C_{2} \varepsilon^{C_{n}} \exp \left(-C_{3} T+C_{4} T \ln \dot{\varepsilon}\right)$.

Eqs. (5), (7), and (8) (GK, WO and Molinari models) have a similar form. The first part of each equation is the same, although they were developed from different assumptions. The only difference among them is in the material parameters such as the thermal softening, $a$, and strain rate hardening, $m$. Table 1 shows the parameters used in the calculations and the predictions of the three models for AISI 304. The Molinari predictions are given for two cases: with and without strain hardening. The GK model does not have a strain-rate sensitivity parameter and represents the state of affairs in the later stages of the evolution of shear localization, when the regions surrounding the shear band are unloaded due to thermal softening. The difference between the predictions of the GK model and WO/Molinari models is roughly a factor of 10 for normal metals.

\section{Experimental results}

\subsection{Constitutive responses and temperature estimation}

Quasi-static and dynamic compression tests were carried out at strain rates, respectively, of $10^{-3} \mathrm{~s}^{-1}$ and $3 \times 10^{3} \mathrm{~s}^{-1}$. Fig. 2 shows the compressive stress-strain responses for the as-received and $800^{\circ} \mathrm{C}$ annealed stainless steel 304L. Both materials exhibit similar quasi-static and dynamic responses and have a similar yield stress ( $300 \mathrm{MPa}$ ) and a strong work hardening. It is obvious that the difference of dynamic re-

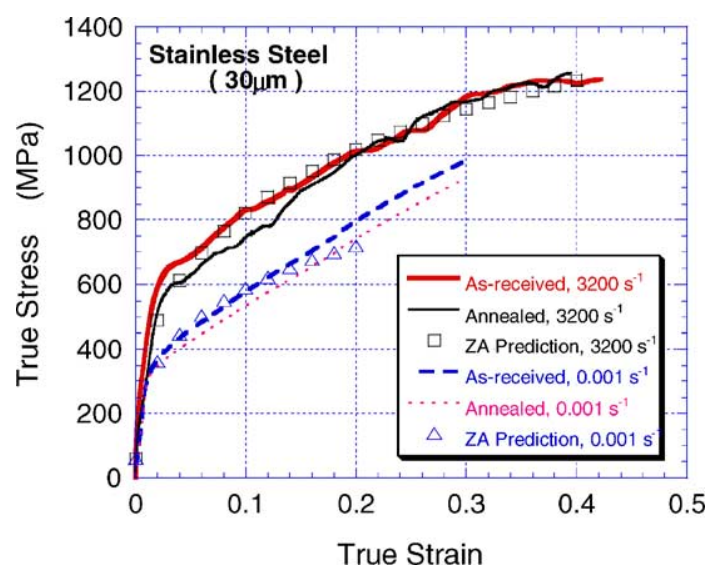

Fig. 2. Quasi-static and dynamic responses of stainless steel $304 \mathrm{~L}$ in as-received and annealed conditions. Zerilli-Armstrong predictions: squares (dynamic) and triangles (quasi-static). 


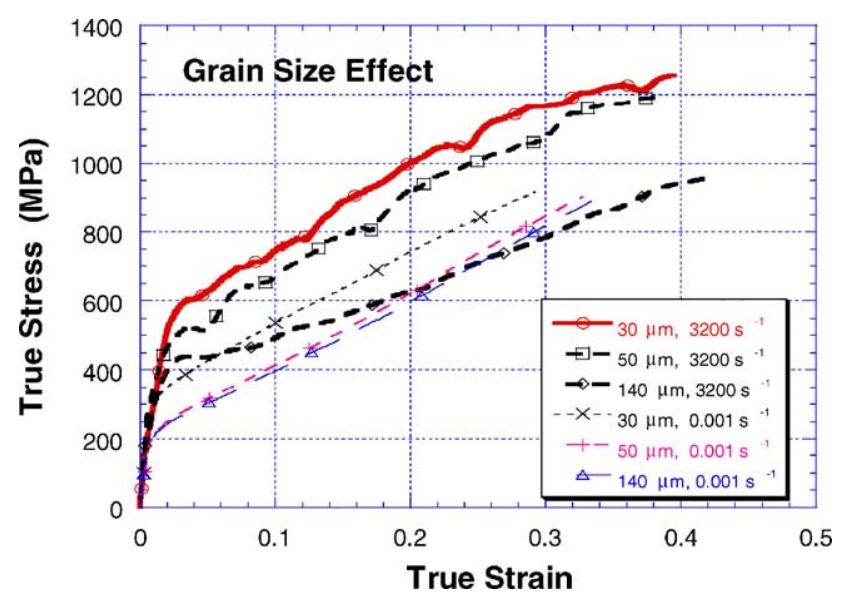

Fig. 3. Quasi-static and dynamic stress strain response of SS 304L with different grain sizes $(30 \mu \mathrm{m}, 50 \mu \mathrm{m}$, and $140 \mu \mathrm{m})$.

sponses between the as-received steel and the annealed steel can be neglected.

The Zerilli-Armstrong equation for FCC metals $[32,33]$ was used to describe the constitutive behaviors of $304 \mathrm{~L}$ stainless steel:

$\mathrm{FCC}: \sigma=\mathrm{C}_{0}+k_{1} d^{-1 / 2}+C_{2} \varepsilon^{C_{n}} \exp \left(-C_{3} T+C_{4} T \ln \dot{\varepsilon}\right)$,

According to mechanical properties tested under both quasistatic and dynamic conditions, the parameters in Eq. (9) are given in Table 1. The comparison between the Zerilli-Armstrong prediction and the experimental curves for stainless steel 304L is shown in Fig. 2.

The variation of grain size in this stainless steel was achieved through different heat treatments. Fig. 3 shows the quasi-static and dynamic compression stress-strain curves for the steels with different grain sizes: $30 \mu \mathrm{m}, 50 \mu \mathrm{m}$, and $140 \mu \mathrm{m}$. The Hall-Petch relation between the yield stress and the annealing temperature is given in Fig. 4. The trian-

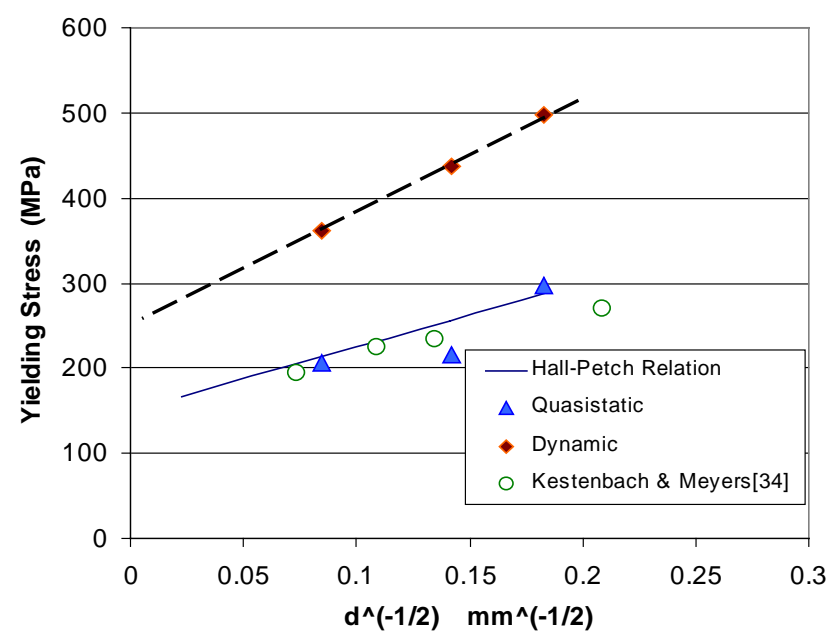

Fig. 4. Hall-Petch plot for AISI 304 SS under quasi-static $\left(10^{-3} \mathrm{~s}^{-1}\right)$ and dynamic $\left(3 \times 10^{3} \mathrm{~s}^{-1}\right)$ conditions. gle and diamond marks show the experimental data for yield stress at $10^{-3} \mathrm{~s}^{-1}$ and $10^{-3} \mathrm{~s}^{-1}$, respectively. The dashed curve represents the Hall-Petch relation at $3 \times 10^{3} \mathrm{~s}^{-1}$. The solid line represents the Hall-Petch relation for quasistatic behavior. Kestenbach and Meyers [34] also measured the grain size dependence of the tensile yield stress for AISI 304SS. Their experimental results are represented as circles in this figure. The current results are in close agreement with their results [34]; $\sigma_{0}$ and $k_{\mathrm{gs}}$ in the Hall-Petch relation are equal to $163.8 \mathrm{MPa}$ and $0.75 \mathrm{MPa} \mathrm{m}^{1 / 2}$.

Based on the adiabatic assumption, the plastic work within a shear band is completely converted into heat to rise the local temperature. The temperature increment due to deformation can be estimated through the predicted constitutive relations. The constitutive description of Zerilli-Armstrong provides the relation between stress and temperature. The temperature change satisfies the following relation:

$\frac{\mathrm{d} T}{\mathrm{~d} t}=\beta \frac{\sigma \dot{\varepsilon}}{\rho C(T)}$,

$\int_{T_{0}}^{T} \frac{\rho C(T)}{\beta \sigma(T)} \mathrm{d} T=\int_{0}^{t} \dot{\varepsilon} \mathrm{d} t=\int_{0}^{\varepsilon} \mathrm{d} \varepsilon=\varepsilon$,

where $\rho$ and $C$ are the density and the thermal capacity of materials, respectively. The thermal conversion rate, $\beta$, is a constant close to 1 . Corresponding constitutive equations for SS 304L in Eq. (9), the thermal capacity (specific heat) $C(T)$ for stainless steel is:

$$
\begin{aligned}
\text { SS 304L } C(T)(\mathrm{J} / \mathrm{kg} \mathrm{K})= & 9.278 \times 10^{-2}+9 \times 10^{-4} T \\
& +\frac{1.24 \times 10^{4}}{T^{2}} .
\end{aligned}
$$

In adiabatic case $(\beta=1)$, numerical integration of Eq. (10) gives the relation between strain and temperature increment. The temperature as the function of true strain for stainless steel 304 is shown in Fig. 5. The grain size does not affect the heating significantly and its effect can be ignored (see Fig. 5). In order to convert the true strain to the corresponding shear strain, the following equation, applicable to simple shear [35], was used:

$\gamma=\sqrt{2 \mathrm{e}^{2 \varepsilon}-1}-1$.

The relations between temperature and the converted engineering shear strain are plotted in Fig. 5(b). For Fig. 5(b) only one grain size was used.

\subsection{Shear-band characters in as-received stainless steel and comparison}

The development of multiple shear bands on the thickwalled cylinder specimens reveals self-organization characteristics. This confirms recent results obtained for $\mathrm{Ti}$ and Ti-6Al-4V [22,23]. Fig. 6(a) and (b) show shear band patterns in the cylindrical specimens for the as-received SS 304L. Small shear bands at the internal boundary of the 

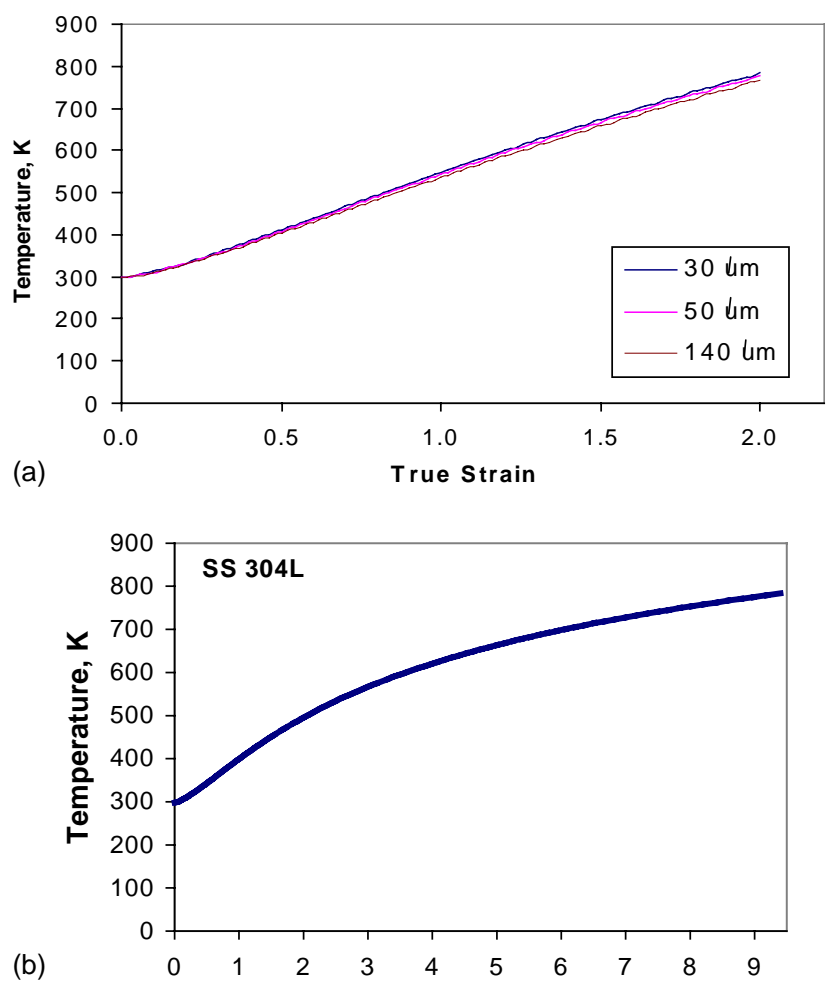

Fig. 5. Predicted temperature in AISI 304 SS $(d=30 \mu \mathrm{m}, 50 \mu \mathrm{m}$, and $140 \mu \mathrm{m}$ ) as the function of (a) true strain; and (b) engineering shear strain $\gamma$.

specimen are observed by optical microscopy at an effective strain of 0.55 (Fig. 6(a)). Since most of shear bands had not been fully developed, it is called the early stage. Fig. 6(b) shows a fully developed shear band pattern with an effective strain of 0.92 . Some shear bands traveled far deep into the cylinder, or even passed through the whole thickness of the specimen to the external boundary of the cylinder. This is termed the late stage of a shear band pattern. Even in this case, the major part of internal surface of the sample still maintains cylindrical shape with good symmetrical geometry. A close-up observation exhibits the evolution of shear band pattern. At the early stage, shear bands construct a periodical array along the internal boundary in Fig. 7(a). The lengths of these bands are quite close. At the late stage $\left(\varepsilon_{\mathrm{ef}}=0.92\right)$, some of bands grow faster than the others and propagate into the body of the cylinder with the small bands between them (see Fig. 7(b)).

Examination of these specimens was carried out under a $500 \times$ optical microscope. Shear bands with length less than $30 \mu \mathrm{m}$ were found to be indistinct and very hard to distinguish from the machined layer. Only the shear bands with lengths above this critical value were recorded and measured. Fig. 8(a)-(d) show, in schematic fashion, the distribution of shear bands for two groups of specimens in the as-received condition. Only a small fraction of the bands are shown. The number of bands is marked in the bottom of each schematic. Fig. 8(a) and (b) represent two specimens with

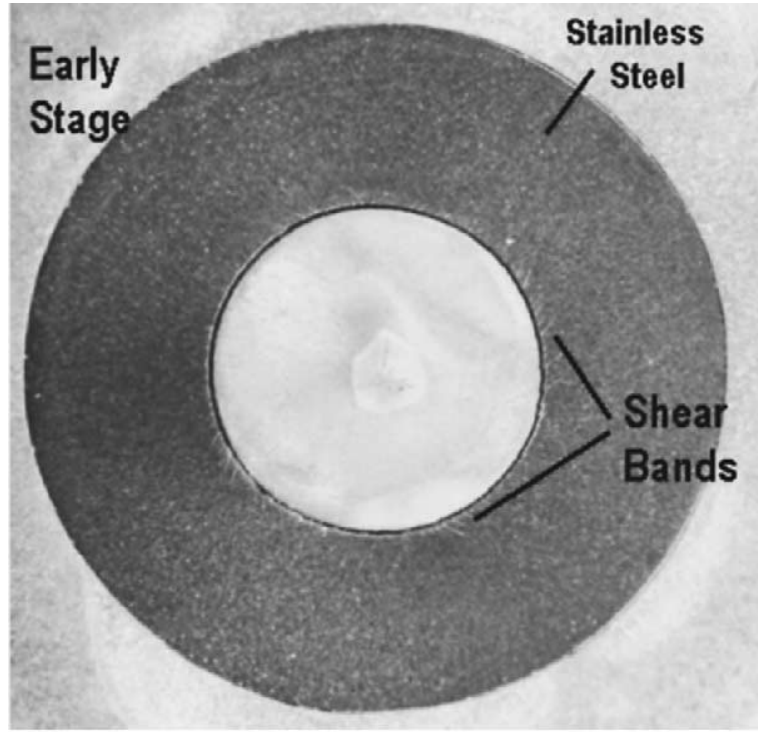

(a) Early stage

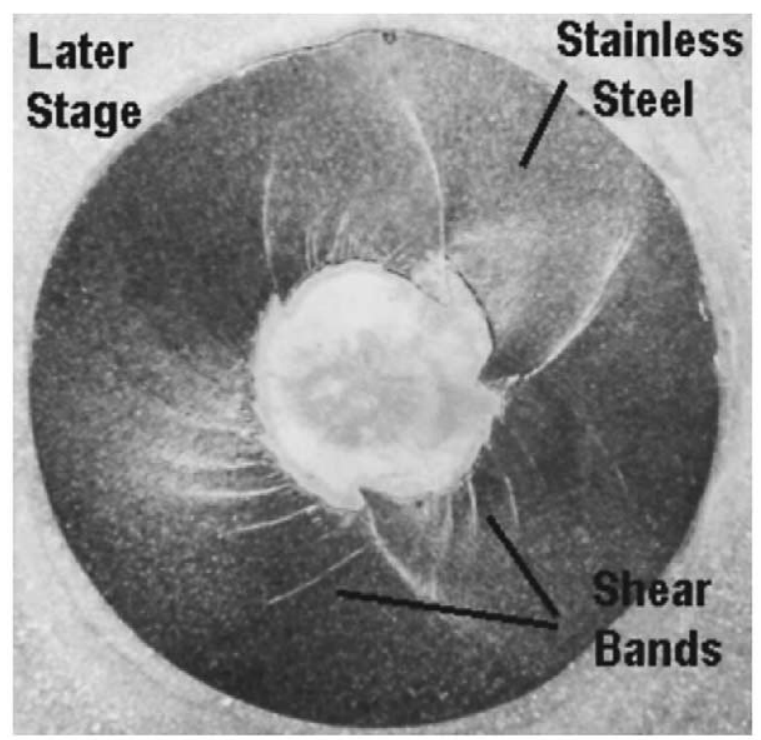

(b) Late Stage

Fig. 6. Overall view of shear band patterns in as-received stainless steel at effective strains of 0.55 and 0.92 .

the same effective strain of 0.55 . The numbers of distinguishable shear bands are 272 and 235, respectively. Fig. 8(c) and (d) show the spatial patterns of shear bands at the late stage $\left(\varepsilon_{\mathrm{ef}}=0.92\right)$. The numbers of shear bands decrease to 165 and 192, respectively. The longer shear bands block the development of the neighboring smaller shear bands. This is evidenced in the regions marked "A" in Fig. 8(c). The longer bands form an enclosure (because they are clock-wise and counter-clockwise) and restrict the growth of the included bands.

A better quantitative assessment of shear-band evolution is provided by plotting shear band lengths $L_{i}$, as a function of position. Fig. 9 gives the spectra of shear band distributions in the as-received SS 304L. At the initial stage (Fig. 9(a)) 


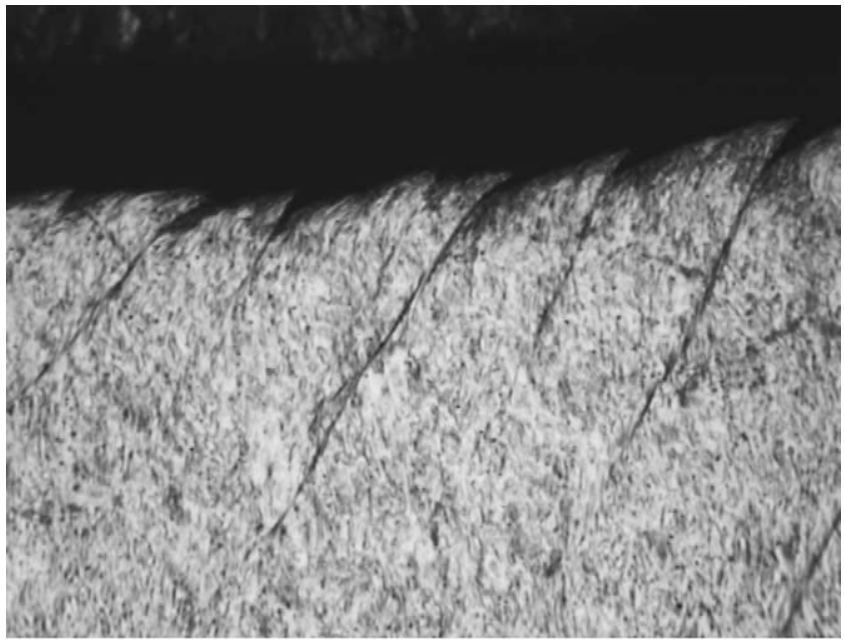

(a)

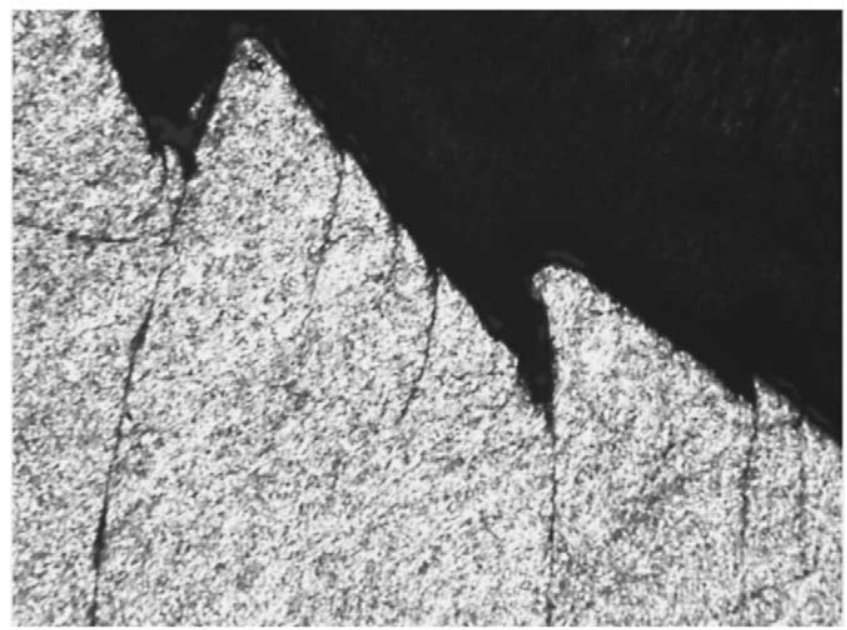

(b)

Fig. 7. Typical multiple shear-band patterns on the internal surface of collapsed cylinder specimens: (a) early stage(effective strain of 0.55 ); and (b) well-developed stage (effective strain 0.92).

the steel exhibits multiple shear bands distributed homogeneously in space. The lengths of distinguishable shear bands vary from $0.03 \mathrm{~mm}$ to $0.86 \mathrm{~mm}$. The difference is not very large. The shear band pattern exhibits a periodical distribution. The spacing of shear bands for the as-received SS 304 is $0.12 \mathrm{~mm}$. Fig. 9(b) shows the spectrum of shear bands at the late stage. Some shear bands develop much longer than the others and even reach the external boundary. Most of shear bands have not extended beyond the length at the initial stage $(<0.9 \mathrm{~mm})$, while a few shear bands grow to a length close to $6.4 \mathrm{~mm}$. It is noticed that the number of shear bands decreases with the increase of effective strain. It can be concluded that some shorter shear bands must have been stopped and some disappeared during the collapse process.

Three theoretical predictions discussed in Section 3 are compared with the experimental results of shear band spacings. The shear yield stress for the stainless steel is taken as $150 \mathrm{MPa}$ (for the WO and M models) and the shear strain

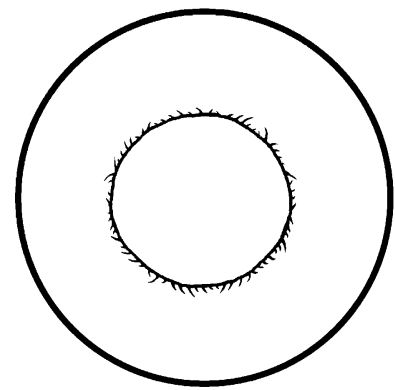

(a) SS $31 \varepsilon_{\text {ef }}=0.55, \mathrm{~N}=272$

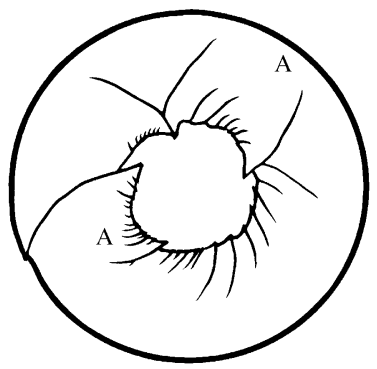

(c) $\mathrm{SS} 33, \varepsilon_{\mathrm{ef}}=0.92, \mathrm{~N}=165$

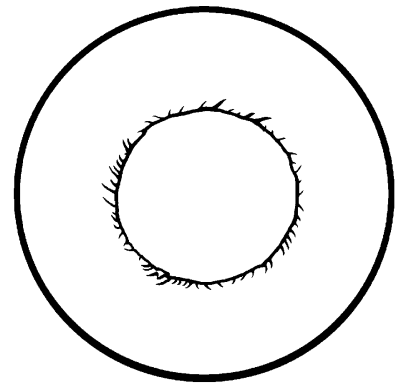

(b) $\mathrm{SS} 32, \varepsilon_{\mathrm{ef}}=0.55, \mathrm{~N}=235$

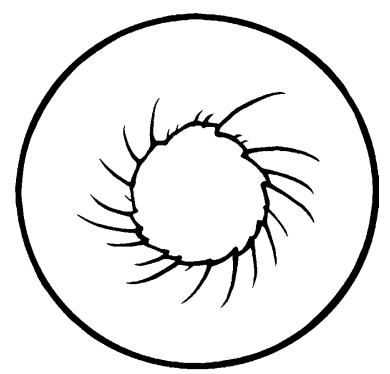

(d) $\mathrm{SS} 34, \varepsilon_{\mathrm{ef}}=0.92, \mathrm{~N}=192$
Fig. 8. Schematic configurations of shear-band pattern in the as-received 304L stainless steel.

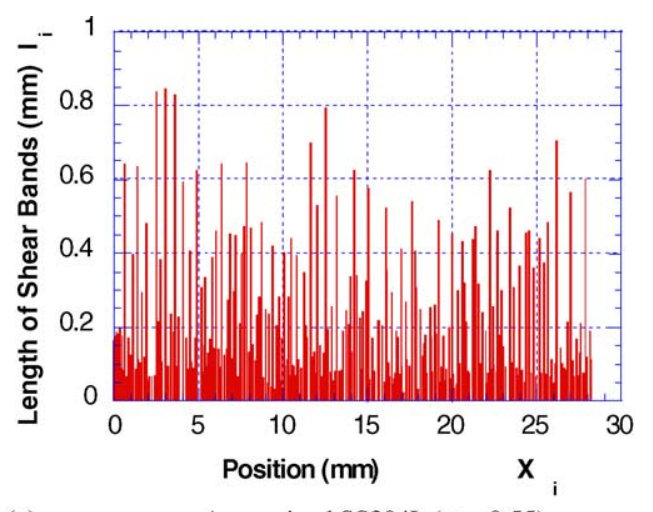

(a) As-received SS304L ( $\left.\varepsilon_{\mathrm{e}}=0.55\right)$

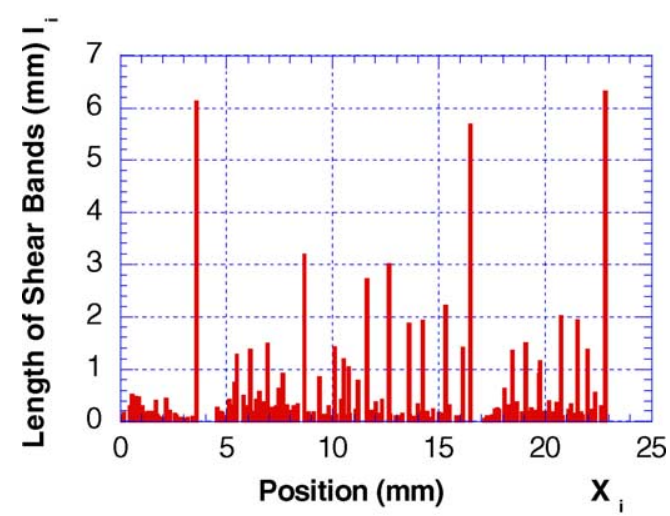

(b) As-received SS304L $\left(\varepsilon_{\mathrm{e}}=0.92\right)$

Fig. 9. Spatial distribution of shear bands in the as-received SS 304L at two stages of evolution. 
Table 2

Shear band spacings: comparison between experimental results and predictions

\begin{tabular}{ll}
\hline & Spacing $(\mathrm{mm})$ \\
\hline Experimental data full shear bands $(\mathrm{mm})$ & 0.12 \\
Experimental data for $l \geq l_{\mathrm{cr}}=1.8 \mathrm{~mm} L_{i}$ & 2.48 \\
$L_{\mathrm{GK}}(\mathrm{mm})$ & 2.4 \\
$L_{\mathrm{WO}}(\mathrm{mm})$ & 0.33 \\
$L_{\mathrm{MO}}(\mathrm{mm})$ & 0.29 \\
\hline
\end{tabular}

rate of the collapsed cylinder tests is $6 \times 10^{4} \mathrm{~s}^{-1}$. The predictions of shear band spacing from the three models are calculated by using these parameters. The experimental results and the predicted values for shear band spacings are listed in Table 2. The two theoretical approaches give different predictions. The perturbation predictions from Wright-Ockendon (WO) [14] model and Molinari [15] model are $0.33 \mathrm{~mm}$ and $0.29 \mathrm{~mm}$, respectively. These data are about 2.5 times of the experimental result of $0.12 \mathrm{~mm}$, but they are still of the same order of magnitude as the experimental data. In contrast, Grady-Kipp (GK) [13] model predicts that the spacing of shear bands in stainless steel equal to $2.40 \mathrm{~mm}$, roughly 20 times of the experimental result. Well developed bands are defined as bands having a length $l \geq l_{\mathrm{cr}}$, where $l_{\mathrm{cr}}$ is a critical length set as $1.8 \mathrm{~mm}$. The spacing of these well-developed bands was $L_{i}=2.48 \mathrm{~mm}$. This is in good agreement with the Grady-Kipp model.

The main differences between the two types of predictions are the strain rate hardening, $m$ and strain hardening, $n$. The Grady-Kipp model uses a constitutive equation without strain rate hardening effects. It appears that the strain rate hardening may play an important role in the evolution of shear band spacing. Unfortunately, GK prediction can not be improved even though the rate hardening term is introduced into constitutive equation. If we apply the same rate-dependent constitutive Eq. (6) as that used in the WO model, the strain rate term disappears under the assumption that shear stress within the shear band goes to zero due to thermal softening at well-developed stage. A simple critical condition, $a=\left(T-T_{0}\right)^{-1}$, can be obtained, which is disassociated with the strain rate hardening. Therefore, the key difference in these two types of models is the basic assumptions instead of the rate hardening term.

The WO/M models, based on perturbation analysis, reflect the behavior of shear bands at the initial plastic deformation stage. Shear bands develop from a weak perturbation of homogeneously deformed materials. All possible nuclei of shear bands are included into the growing perturbations. The GK model considers the extreme case in which the shear band totally loses its resistance to load. At this stage shear bands should be completely developed and are not any more weak perturbations. Not all of the shear band nuclei can evolve to the well-developed stage. A fraction of the shear bands cannot survive due to the competition among them. This very important fact needs to be empha- sized: there are several levels during the development of spacing pattern of shear bands. Since the GK model uses an extreme assumption that physically relates to the late stage, the predicted spacing should be associated only with the well developed, propagating shear bands. We need to consider a critical cut-off length for the evolving shear bands. The application of the cut-off length of shear bands means that these shear bands with a length shorter than this value are "decaying" or "dead". Only the "propagating" or "living" shear bands are considered to construct the new spatial pattern. For example, if the critical length for our stainless steel is $1.8 \mathrm{~mm}$; there are 11 long shear bands in the as-received steel from the spectrum of shear bands in Fig. 9(b). The final "living" (i.e. propagating) shear bands construct a new spacing of $2.48 \mathrm{~mm}$, which is fairly close to the GK prediction. This result is also listed in Table 2.

\subsection{Grain size effects on shear band character}

The annealing of stainless steels at $800^{\circ} \mathrm{C}, 1050{ }^{\circ} \mathrm{C}$ and $1280^{\circ} \mathrm{C}$ results in different grain sizes. The spatial distributions of shear bands in these annealed steels were examined under the same effective strains. Fig. 10(a)-(c) show the shear band distribution at early stage $\left(\varepsilon_{\mathrm{ef}}=0.55\right)$. The numbers of the shear bands for the three grain sizes, $30 \mu \mathrm{m}$, $50 \mu \mathrm{m}$, and $140 \mu \mathrm{m}$, are 186,220 , and 184 , respectively. These numbers roughly remain at the same level. The corresponding spacings of shear bands are $0.152 \mathrm{~mm}$ for the steel with the grain size of $30 \mu \mathrm{m}, 0.136 \mathrm{~mm}$ for the steel with grain size of $50 \mu \mathrm{m}$, and $0.154 \mathrm{~mm}$ for the steel with the grain size of $140 \mu \mathrm{m}$. An additional test was performed on a specimen with larger grain size, $280 \mu \mathrm{m}$. The initial purpose for this experiment was to examine how shear bands distributed if the grain size is larger than the spacing of bands. The spectrum of shear bands in the specimen with a grain size of $280 \mu \mathrm{m}$ is shown in Fig. 10(d). The total number of shear bands under the effective strain of 0.55 is 201 . The corresponding spacing of bands is $0.15 \mathrm{~mm}$, which is almost the same value as those in the samples with grain sizes of $50 \mu \mathrm{m}$ and $140 \mu \mathrm{m}$. The spacing is not affected significantly by the grain size although it varies over a range of five times.

The average length of bands increases with the increase of the grain size. The maximum length of the shear bands is less than $0.2 \mathrm{~mm}$ for a grain size of $30 \mu \mathrm{m}$. It increases to $0.3 \mathrm{~mm}$ for a grain size is $50 \mu \mathrm{m}$ and $1.0 \mathrm{~mm}$ for a grain size of $140 \mu \mathrm{m}$.

At late stage $\left(\varepsilon_{\mathrm{ef}}=0.92\right)$, the shear band distributions are shown in Fig. 11(a)-(c). Similar to the cases at $\varepsilon_{\text {ef }}=0.55$, the numbers of shear bands are 194, 192, and 172 for the three grain sizes, $30 \mu \mathrm{m}, 50 \mu \mathrm{m}$, and $140 \mu \mathrm{m}$, respectively. The numbers of shear bands are quite similar to those at early stage. It is clear that the saturation of shear band nucleation happens in all these annealed steels. The critical effective strain for the saturation is lower than $\varepsilon_{\mathrm{ef}}=0.55$. That can be proved by the fact that the numbers of bands are not changed for the different effective strain larger than 0.55. Subtracted 

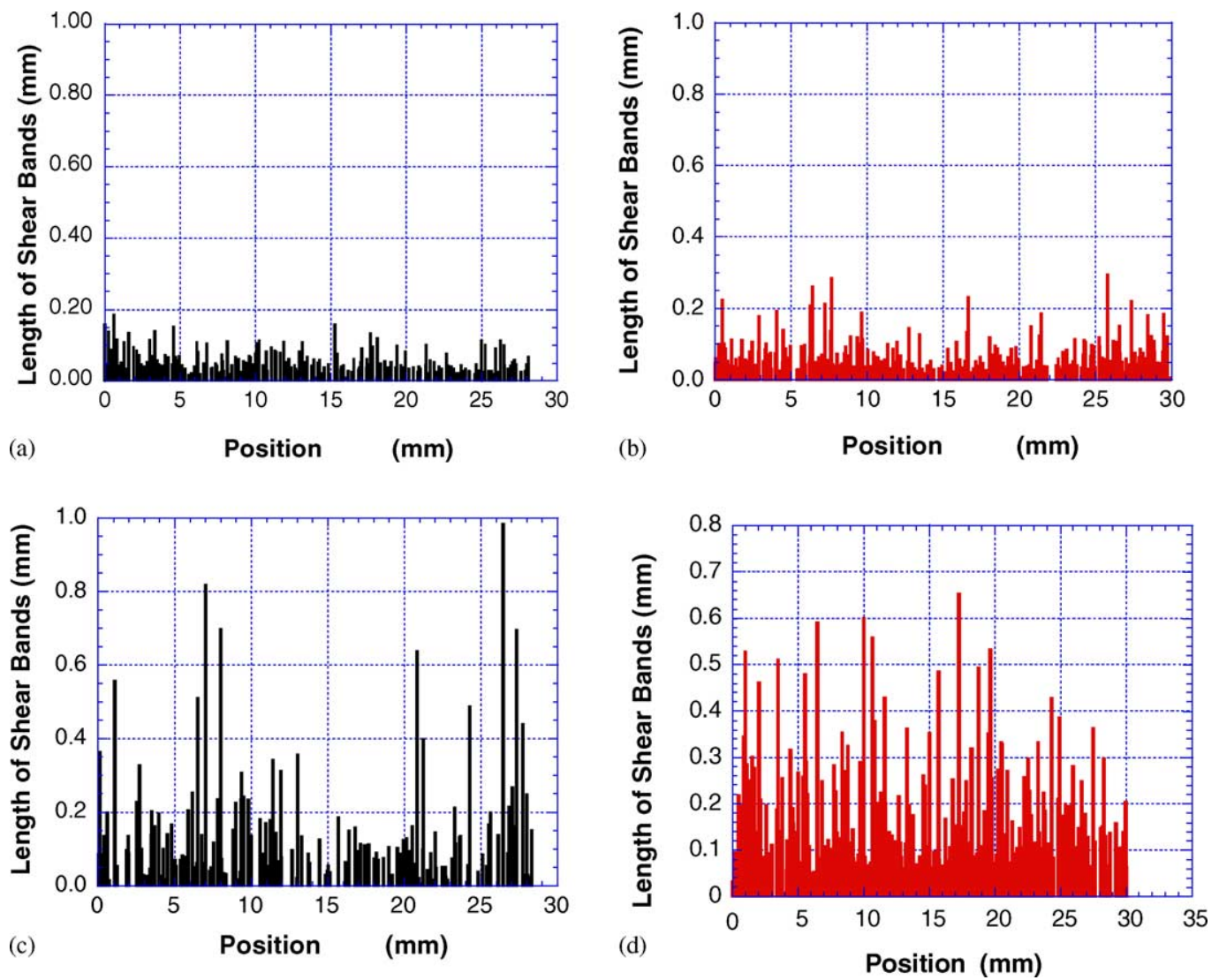

Fig. 10. Spatial distribution of shear bands in annealed SS 304L with different grain sizes at early stage $\left(\varepsilon_{\text {ef }}=0.55\right)$ : (a) $d=30 \mu \mathrm{m}$; (b) $d=50 \mu \mathrm{m}$; (c) $d=140 \mu \mathrm{m}$, and (d) $d=280 \mu \mathrm{m}$.

the geometrical part, the corresponding spacings of shear bands are calculated as $0.15 \mathrm{~mm}, 0.15 \mathrm{~mm}$, and $0.17 \mathrm{~mm}$ for the steels with the grain size of $30 \mu \mathrm{m}, 50 \mu \mathrm{m}$, and $140 \mu \mathrm{m}$, respectively. It shows again that the spacings of shear bands vary with the grain size slightly. Spacing of shear bands in the steel has a slow increase with the increase of the grain size.

Most annealed samples have the grain sizes that are equal to or less than the scale of spacing. A careful observation of microstructure on the sectional surface of this sample indicates that the larger grains have been squeezed in tangent direction and elongated on the radial direction. The compressed grains at the internal surface of the cylinder have a similar size as the spacing. The nucleation sites tend to locate at the grain boundary. However, the perturbation of the grain boundaries seems not to dominate the nucleation of shear bands. If grain size were to affect the nucleation sites, the sample with the grain size of $280 \mu \mathrm{m}$ should have fewer bands than that with the grain size of $50 \mu \mathrm{m}$. The experimental result shows that the effect of grain boundary is not significant to the formation of shear band patterns in space.

Nesterenko and Bondar [16] examined the grain size effect on the spacing of shear bands in copper. They found that the number of shear bands in copper was the same for grain size
$1000 \mu \mathrm{m}$ and $100 \mu \mathrm{m}(N=30)$, but noticeably increased to 50 with grain size decrease to $30 \mu \mathrm{m}$.

The spatial distributions of shear bands in these annealed stainless steels are summarized in Table 3 . The spacing of shear bands is approximately constant and equal to $0.150 \mathrm{~mm}$. It appears that there is no effect of grain size on the spacing in the grain size range investigated. The dependence on grain size enters three models through $\tau_{01}$, the yield stress. The dependence of the spacing on grain size according to the WO equation, in which the Hall-Petch relation was introduced, is given below:

$L_{\mathrm{WO}}=2 \pi\left(\frac{m^{3} k C}{\dot{\gamma}_{0}^{3} a^{2}\left(\tau_{01}+k_{\mathrm{gs}} d^{-1 / 2}\right)}\right)^{1 / 4}$.

Table 3

Average spacings of shear bands in the annealed stainless steel with different grain sizes

\begin{tabular}{lcl}
\hline Specimen & Grain size $(\mu \mathrm{m})$ & Spacing $(\mathrm{mm})$ \\
\hline Annealed $800^{\circ} \mathrm{C} / 3 \mathrm{~h}$ & 30 & 0.15 \\
Annealed $1050^{\circ} \mathrm{C} / 3 \mathrm{~h}$ & 50 & 0.14 \\
Annealed $1280^{\circ} \mathrm{C} / 3 \mathrm{~h}$ & 140 & 0.16 \\
Annealed $1330^{\circ} \mathrm{C} / 24 \mathrm{~h}$ & 280 & 0.15 \\
\hline
\end{tabular}



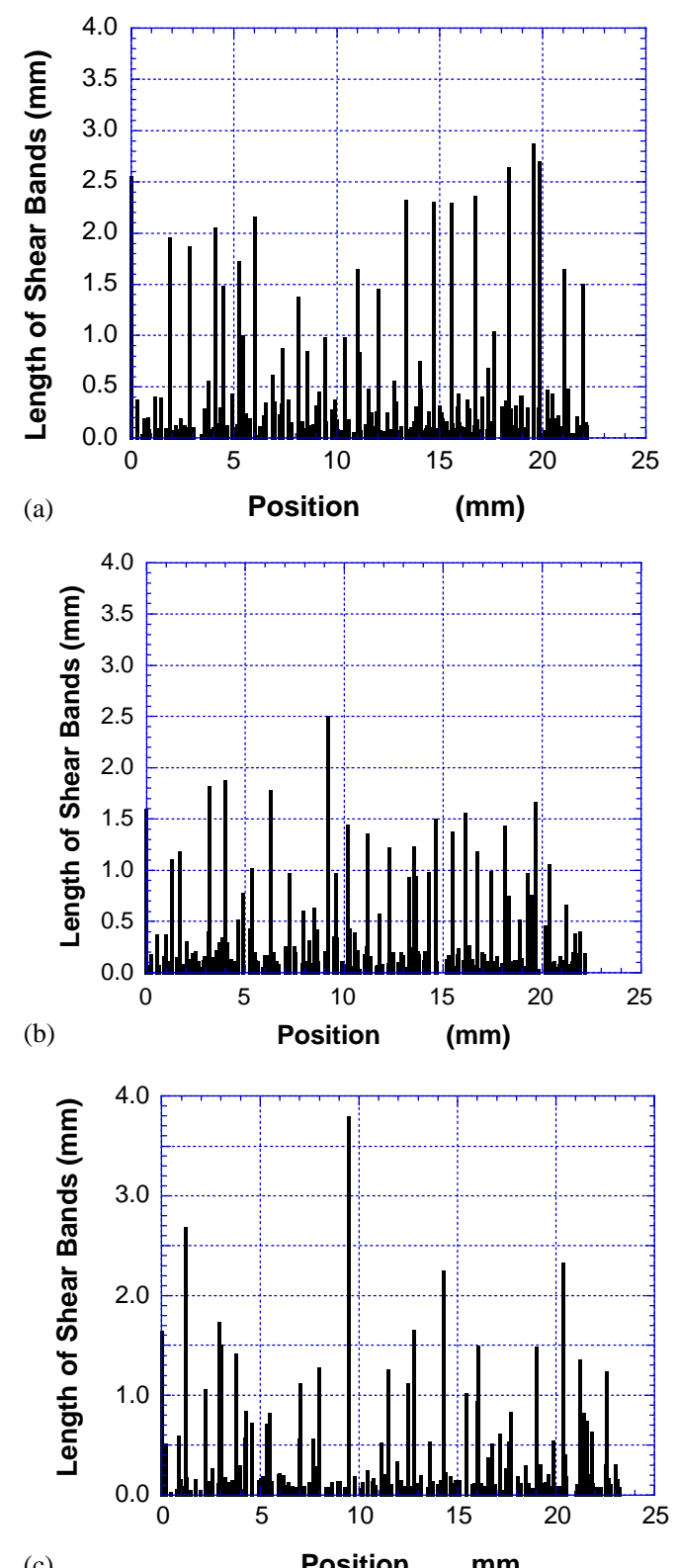

(c)

Fig. 11. Spatial distribution of shear bands in annealed SS 304L with different grain sizes at late stage $\left(\varepsilon_{\mathrm{ef}}=0.92\right)$ : (a) $d=30 \mu \mathrm{m}$; (b) $d$ $=50 \mu \mathrm{m}$; and (c) $d=140 \mu \mathrm{m}$.

Fig. 12 shows the predicted spacing as a function of grain size. Since the flow stress influence has the power of $1 / 4$, the variation of spacing is limited. The predicted results of spacings vary from $0.335 \mathrm{~mm}$ to $0.363 \mathrm{~mm}$, corresponding to the grain size range marked between the left solid line and the dash line. Therefore, it can be concluded that there is no significant effect of grain size on the shear band spacing in the range of grain sizes studied $(30-280 \mu \mathrm{m})$.

Collapsed cylinder experiments were also carried out on a single crystal alloy, $\mathrm{Fe}-15 \mathrm{Cr}-15 \mathrm{Ni}$, which has a similar composition of elements as $304 \mathrm{~L}$ steel's $18 \mathrm{Cr}-8 \mathrm{Ni}$. The quasi-static shear yield stress in this material is approxi-

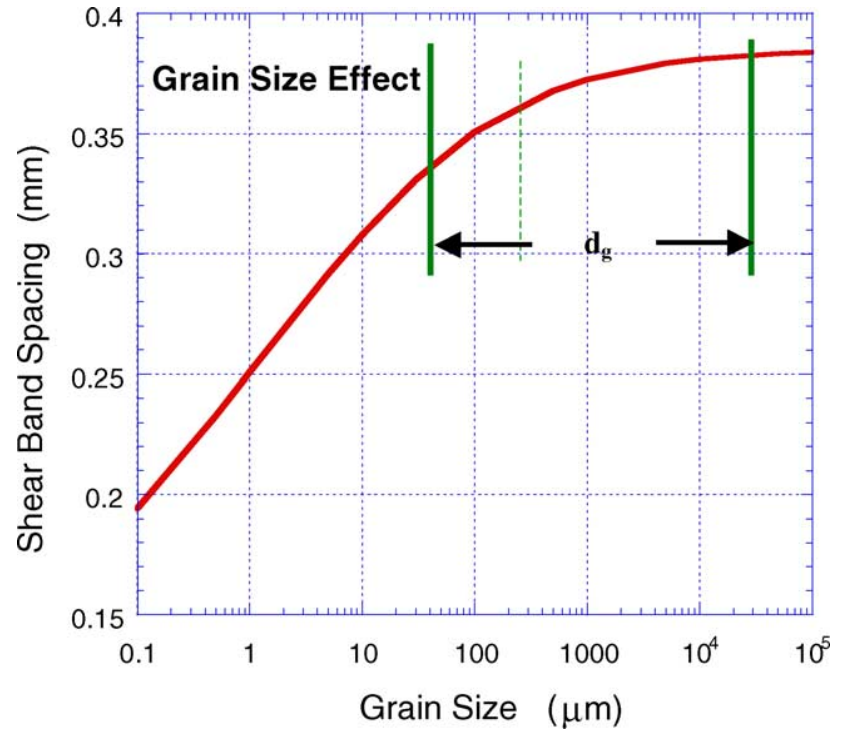

Fig. 12. Wright-Okendon prediction of shear-band spacing as a function of grain size. Solid lines indicate the range of variation of grain size in the stainless steels in current experiments $\left(d_{\mathrm{g}}: 30 \mu \mathrm{m} \Rightarrow 21 \mathrm{~mm}\right)$; dashed line shows the maximum grain size of polycrystalline stainless steel.

mately $70 \mathrm{MPa}$, much lower than $150 \mathrm{MPa}$ in $304 \mathrm{~L}$ steel. The shear-band pattern of this material at an effective strain of 0.92 is shown in Fig. 13(a). There is clear anisotropy, which is analyzed separately [36]. Some shear bands con-

(a)
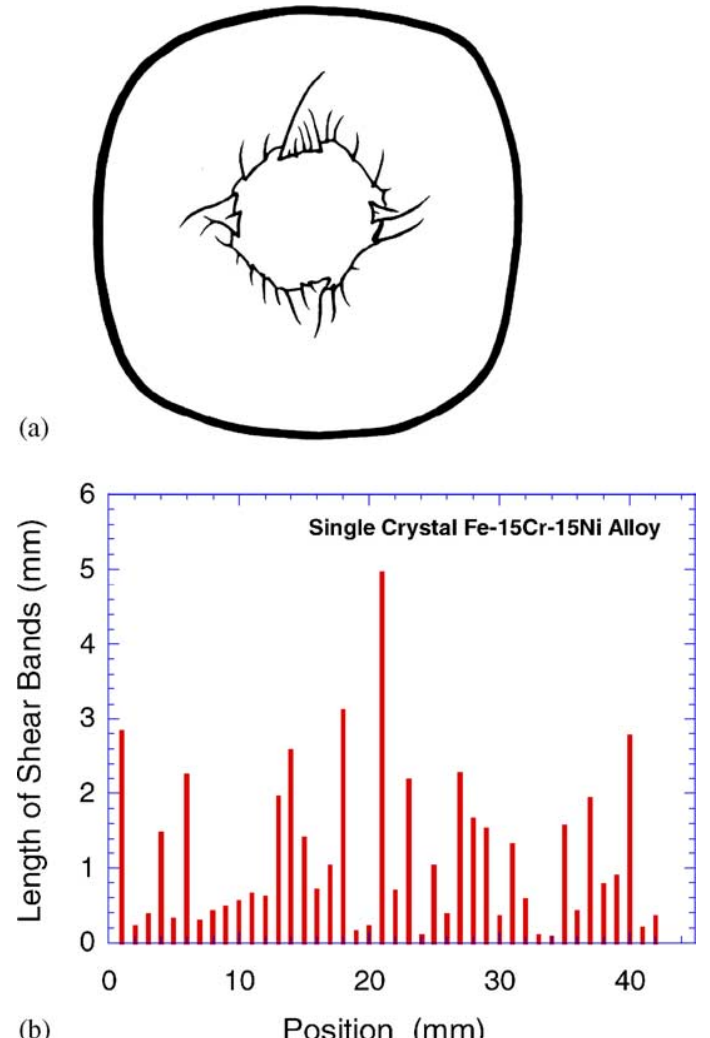

(b)

Position (mm)

Fig. 13. Distribution of shear bands in single crystal $\mathrm{Fe}-15 \% \mathrm{Cr}-15 \% \mathrm{Ni}$ alloy: (a) configuration of shear band pattern; and (b) spatial distribution of shear bands: $\left(\varepsilon_{\mathrm{ef}}=0.92\right), N=42$. 
nected with cracks are distributed at the internal boundary of the specimen. The number of shear bands is significantly lower for the single crystal specimen. There are only 42 shear bands in total in the specimen, giving an average spacing of $0.69 \mathrm{~mm}$. The spectrum of shear bands for the single crystal alloy is shown in Fig. 13(b). Since the spacing between two shear bands is large, an average spacing is estimated directly from the number of shear bands. This result clearly shows that the spacing of shear bands, in general, tends to increase with the increasing grain size. The corresponding $\mathrm{L}_{W O}$ spacing, using Eq. (12), is $0.384 \mathrm{~mm}$ for a grain size of $21 \mathrm{~mm}$ (equal to specimen size). Thus, the grain size effect alone cannot account for the change observed, and it is not clear why the single crystal has much larger shear-band spacing than the polycrystals in the same collapse process configuration. The experiments carried out here on polycrystals all had a spacing smaller than the grain size; it was not possible to grow the grain size in $304 \mathrm{SS}$ beyond $300 \mu \mathrm{m}$. This leaves open the question whether grain-scale inhomogeneities play a role. For the monocrystal, these inhomogeneities do not exist.

\section{Evolution of shear band spacing: two-dimensional effects}

It is clear that the interactions among shear bands in 304L stainless steel exhibit a typical two-dimensional character; this aspect is not incorporated into the GK or WO/M theories. The same observation was made in Ti and Ti-6Al-4V [23]. This led Xue et al. [23] to develop a formalism and apply it to Ti and Ti-6Al-4V. It will be briefly reviewed here prior to its application to AISI 304 SS. The influence of developed shear bands on adjacent nuclei had never been considered earlier; neither had the interactions among growing bands. This dynamic model discussed here contains these elements; thus, the shear band spacing changes as the bands grow.

We assume that shear bands nucleate at the internal boundary of the specimen, at sites determined by the small perturbations of initial deformation. These may be, in metallurgical terms, favorably oriented grains and defects. We consider a number of possible sites with varying potencies. The more potent sites nucleate at a lower strain; each site is assumed to have a characteristic volume $V_{0}$. A probability of nucleation, $P\left(V_{0}\right)$, in a reference volume, $V_{0}$, is well described by an equation based on Weibull [37]. Strain is taken as the independent variable, rather than stress in the original Weibull formulation:

$P\left(V_{0}\right)=1-\exp \left[-\left(\frac{\varepsilon-\varepsilon_{i}}{\varepsilon_{0}-\varepsilon_{i}}\right)^{q}\right]$

$\epsilon$ is the variable; $\epsilon_{i}$ is the critical strain below which no initiation takes place; $\epsilon_{0}$ is an "average" nucleation strain (material constant-when $\varepsilon=\varepsilon_{0}, P\left(V_{0}\right)=0.37$ ); and $q$ is the Weibull modulus. The relation between $P\left(V_{0}\right)$ and

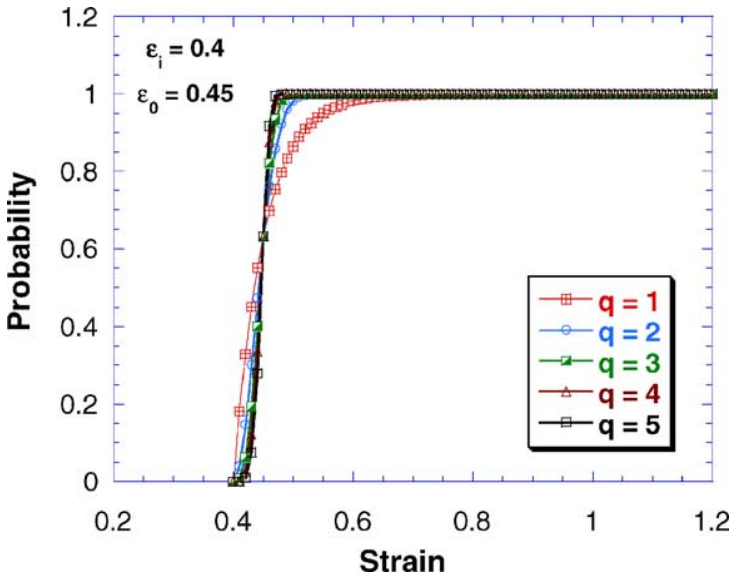

Fig. 14. Probability of nucleation of shear bands as a function of shear strain for five values of $q$.

$\varepsilon$ for the stainless steel is given in Fig. 14. The critical strain and the mean nucleation strain are taken as 0.4 and 0.45 , respectively, to best fit the experimental results; $q$ is given values of $1-5$, providing different distributions. In the geometry used in the current experiments (surface nucleation of shear bands), $V_{0}$ can be replaced by a distance along the internal surface, $L$.

In Ti6Al4V it was found that there is a continuing shielding effect, so that the bands that actually grow are often a fraction of the total possible initiation sites. In contrast, for Ti the shielding effect was not so important. Fig. 15 of ref. [23] shows the schematic interaction between embryos and growing shear bands. Each growing band generates a shielded region around itself due to unloading. We assumed that the width of the unloaded region is proportional to the length of the shear band with a coefficient $k_{1}$ [23]. Three factors govern the evolution of self organization: (a) the imposed strain rate, $\dot{\varepsilon} ;($ b) the growth velocity of shear band, $V$; (c) the initial spacing, $L$. When the ratio $V / \dot{\varepsilon}$ is low, the embryos are all activated before shielding occurs, and the natural spacing $L$ establishes itself. As $V / \dot{\varepsilon}$ increases, shielding becomes more and more important, and the number of deactivated embryos increases. Xue et al. [23] give a detailed analysis of the shielding effect.

This shielding effect can be expressed as:

$S=\frac{2\left(\varepsilon_{0}-\varepsilon_{i}\right) V}{k_{1} \dot{\varepsilon} L}$

This expression correctly predicts an increase in shielding $S$ with increasing $V$, decreasing $\dot{\varepsilon}$, and decreasing $L$. The probability of nucleation with shielding is:

$$
\begin{aligned}
P(L) & =(1-S) P\left(V_{0}\right) \\
& =\left(1-\frac{2\left(\varepsilon_{0}-\varepsilon_{i}\right) v}{\dot{\varepsilon} L}\right)\left\{1-\exp \left[-\left(\frac{\varepsilon-\varepsilon_{i}}{\varepsilon_{0}-\varepsilon_{i}}\right)^{q}\right]\right\}
\end{aligned}
$$

Fig. 15 shows predicted evolutions of nucleation probabilities as a function of increasing strain, for different values of 


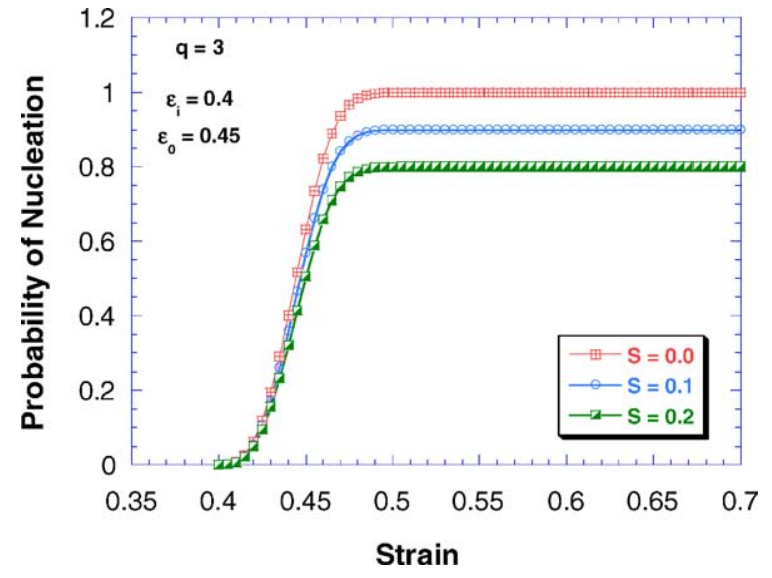

Fig. 15. Effect of shielding on the probability of nucleation as a function of plastic strain (with different values of shielding, $S=0,0.1$, and 0.2 ).

the shielding factor, $S: 0,0.1$, and 0.2 . This model correctly explain the increasing spacing as the shear bands develop, shown in the spatial distribution plots of Figs. 10 and 11. By adjusting $q$ one can obtain different spacing evolution patterns.

Further deformation leads to the heterogeneous growth of these shear bands. Some shear bands grow faster than others. The unloading of the fast-developed shear bands reduces the speed of the adjacent small shear bands, and creates the heterogeneous growth (see shear bands in Fig. 8(c)). The favorable shear bands grow faster, while the unloaded shear bands slow down, and finally stop. The "living" shear bands compete with each other and construct a new spatial pattern by following the self-organization rule. The dead small shear bands may stay at their original location, or may be merged into the large plastic deformation of the surrounding area. In the latter case the number of shear bands effectively reduces as it happens at the late stage of the as-received stainless steel specimen.

The driving force for shear-band propagation is the release of elastic energy. The rate of nucleation is quite different from the growth rate (or growth velocity). It is reasonable to assume that the growth is governed by stress, whereas initiation is governed by strain. The necessary condition is:

$\tau_{\mathrm{g}}<\tau_{\mathrm{I}}$

where $\tau_{\mathrm{g}}$ and $\tau_{\mathrm{I}}$ are the critical shear stresses for growth and initiation, respectively. The greater the difference, the higher the velocity of propagation. The unloading waves sweep through the surrounding area of a shear band and make any new nucleation impossible within this area.

The interaction of shear bands leads to the competitive growth of the propagating shear bands. In previous theories the interaction among shear bands can only be treated as a one-dimensional event at the simplest, elementary level. Although the model presented here has many limitations, it represents an evolution from previously proposed formulations.

\section{Conclusions}

Shear-band characteristics and spacings in stainless steel 304L were experimentally investigated. The effects of material parameters on the initiation and spatial distribution of shear bands are analyzed. The spacing of propagating shear bands is shown to decrease during the deformation process; comparison with current analytical predictions shows that the WO/M model predicts the initial level of self organization of shear bands, while the GK model shows a better agreement with the behavior at the developed stage of shear bands. However, these one-dimensional models do not address the evolution of spacing. The as-received 304 steel shows higher sensitivity to initiation of shear bands than the annealed steels. The softening and the low density of dislocations of crystal grains in the annealed steel are considered to be responsible for this behavior. The grain size exerts some effect on the spacing of shear bands, but no significant change occurs in the range of the tested grain sizes. Separate experiments [38] reveal that the material inside the shear band consists of grains with sub-micrometer sizes; it is proposed that this is the result of a rotational dynamic recrystallization process. Glassy regions were also observed.

The Wright-Ockendon-Molinari and Grady-Kipp theories do not include the interaction effects of developed shear bands and growth velocity on the nucleation. A discontinuous growth mode was proposed earlier [23] and is applied here. The spacing changes periodically, when it reaches the interaction distance between adjacent shear bands (which are a function of their lengths). The self-organized initiation and propagation modes are discussed in terms of a model incorporating the competitive growth of shear bands.

\section{Acknowledgements}

This work was supported by USA Army Research Office under MURI program no. DAAH004-96-1-0376 (Program Manager David Stepp). Discussions with and support by Dr. D.E. Grady are greatly appreciated. Prof. V. Lubarda's and Dr. D. Curran's help are gratefully acknowledged.

\section{References}

[1] Y. Bai, B. Dodd, Adiabatic Shear Localization, Pergamon Press, Oxford, 1992.

[2] M.A. Meyers, Dynamic Behavior of Materials, Wiley, New York, 1994.

[3] T.W. Wright, The Physics and Mathematics of Adiabatic Shear Bands, Cambridge University Press, 2002.

[4] C. Zener, J.H. Hollomon, J. Appl. Phys. 15 (1944) 22.

[5] R.J. Clifton, Material Response to Ultra-High Loading Rates, US National Materials Advisory Board, Washington, DC, 1980 (Chapter 8).

[6] Y. Bai, in: M.A. Meyers, L.E. Murr (Eds.), Shock Waves and High-Strain-Rate Phenomena in Metals, Plenum, New York, 1981, p. 277. 
[7] C. Fressengeas, A. Molinari, J. Mech. Phys. Solids 30 (1987) 185.

[8] T.W. Wright, Int. J. Plasticity 8 (1992) 583.

[9] A. Marchand, J. Duffy, J. Mech. Phys. Sol. 36 (1988) 261.

[10] P.B. Bowden, Philos. Mag. 22 (1970) 455.

[11] D.A. Shockey, in: L.E. Murr, K.P. Staudhammer, M.A. Meyers (Eds.), Metallurgical Applications of Shock-Wave and High-Strain-Rate Phenomena, 1986, p. 633.

[12] D.E. Grady, J. Geophys. Res. 85 (1980) 913.

[13] D.E. Grady, M.E. Kipp, J. Mech. Phys. Solids 35 (1987) 95.

[14] T.W. Wright, H. Ockendon, Int. J. Plasticity 12 (1996) 927.

[15] A. Molinari, J. Mech. Phys. Solids 45 (1997) 1551.

[16] V.F. Nesterenko, M.P. Bondar, DYMAT J. 1 (1994) 245.

[17] V.F. Nesterenko, A.N. Lazaridi, S.A. Pershin, Fizika Goreniyai Vzryva 25 (1989) 154.

[18] V.F. Nesterenko, M.A. Meyers, T.W. Wright, in: L.E. Murr, K.P. Staudhammer, M.A. Meyers (Eds.), Metallurgical and Materials Applications of Shock-Wave and High-Strain-Rate Phenomena, Elsevier, Oxford, 1995, p. 397.

[19] V.F. Nesterenko, M.A. Meyers, T.W. Wright, Acta Mater. 46 (1998) 327.

[20] V.F. Nesterenko, M.A. Meyers, J.C. LaSalvia, M.P. Bondar, Y.J. Chen, Y.L. Lukyanov, Mater. Sci. Eng. A 229 (1997) 23

[21] Q. Xue, V.F. Nesterenko, M.A. Meyers, in: M.D. Furnish, et al. (Eds.), Shock Compression of Condensed Matter-1999, AIP Conference Proceedings 505, AIP Press, New York, 1999, p. 431.

[22] M.A. Meyers, Q. Xue, Y. Xu, V.F. Nesterenko, in: A. Chiba, S. Tanimura, K. Hokamoto (Eds.), Impact Engineering and Application, Elsevier, 2001, p. 123.

[23] Q. Xue, M.A. Meyers, V.F. Nesterenko, Acta Mater. 50 (2002) 575.
[24] V.F. Nesterenko, M.A. Meyers, H.C. Chen, J.C. LaSalvia, Met. Mater. Trans. 26A (1995) 2511.

[25] C.J. Shih, M.A. Meyers, V.F. Nesterenko, Acta Mater. 46 (1997) 4037.

[26] M.A. Meyers, V.F. Nesterenko, J.C. LaSalvia, Q. Xue, Mater. Sci. Eng. A 317 (2001) 204.

[27] V.F. Nesterenko, Dynamics of Heterogeneous Materials, Springer, New York, 2001.

[28] M.A. Meyers, Q. Xue, V.F. Nesterenko, in: Shock Compression of Condensed Matter-2001, AIP Press, 2002, pp. 567-570.

[29] Q. Xue, V.F. Nesterenko, M.A. Meyers, Int. J. Impact Eng. 28 (2002) 257.

[30] M.G. Stout, P.S. Follansbee, Trans. ASME., J. Eng. Mater. Tech. 108 (1986) 344.

[31] N.F. Mott, Proc. R. Soc. 189 (1947) 300.

[32] F.J. Zerilli, R.W. Armstrong, J. Appl. Phys. 61 (1987) 1816.

[33] F.J. Zerilli, R.W. Armstrong, in: S.C. Schmidt, J.N. Johnson, L.W. Davison (Eds.), Shock Compression of Condensed Matter-1989, Elsevier, Amsterdam, 1990, p. 357.

[34] H.J. Kestenbach, M.A. Meyers, Met. Trans. 7A (1976) 1943.

[35] R.S. Culver, in: R.W. Rohde, B.M. Butcher, J.R. Holland, C.H. Karnes (Eds.), Metallurgical Effects at High Strain Rates, Plenum Press, New York, 1973, pp. 519-530.

[36] M.A. Meyers, B. Cao, V.F. Nesterenko, D. Benson, Y.B. Xu, Shear localization-martensitic transformation interactions in $\mathrm{Fe}-\mathrm{Cr}-\mathrm{Ni}$ monocrystal, Met. Mater. Trans. (2004), in press.

[37] W. Weibull, J. Appl. Mech. 18 (1951) 293.

[38] M.A. Meyers, Y.B. Xu, Q. Xue, M.T. Pérez-Prado, T.R. McNelley, Acta Mater. 51 (2003) 1307. 